Lee A. Fleisher MD, Ann H. Nelson, RN BSN, Stanley H. Rosenbaum MD

\title{
Failure of negative dipyridamole thallium scans to predict perioperative myo- cardial ischaemia and infarction
}

\begin{abstract}
Three cases of postoperative myocardial infarction are reported in patients with normal or fixed defects on preoperative dipyridamole thallium scans (interpreted as "negative" for active cardiac ischaemic risk). All patients were monitored with an ambulatory electrocardiographic recorder from the evening before surgery through the first two postoperative days. Two of the patients demonstrated preoperative or early postoperative ischaemia, suggesting that the test was a false negative. The third patient did not demonstrate ischaemia during the period of monitoring, but developed a myocardial infarction during the third postoperative day, suggesting progression of the underlying coronary artery disease. Preoperative dipyridamole thallium imaging may result in false negative scans in selected high-risk populations.
\end{abstract}

Le présent rapport concerne trois cas d'infarctus du myocarde postopératoire chez des patients avec des scintigraphies au thallium avec dipyridamole normales ou avec déficits fixes en période préopératoire (interprétées comme étant «négatif 》 face aux risques d'ischémie cardiaque active). Tous les patients ont été surveillés à l'aide d'une enregistreuse électrocardio-

\section{Key words}

HEART: ischaemia, infarction;

MEASUREMENT TECHNIQUES: dipyridamole thallium imaging.

From the Departments of Anesthesiology, Medicine and Surgery, Yale University School of Medicine, Yale New Haven Hospital, New Haven, CT 06510.

Address correspondence to: Dr. Lee A. Fleisher, Department of Anesthesiology, and Critical Care Medicine, The Johns Hopkins Hospital, 600N Wolfe Street, Baltimore, MD 21205.

Accepted for publication 7th October, 1991. graphique ambulatoire, à partir de la veille de la chirurgie jusqu'à la fin de la deuxième journée postopératoire. Deux des patients ont démontré de l'ischémie préopératoire ou tôt dans la période postopératoire, suggérant que le test était un " faux négatif ». Le troisième patient n'a pas démontré d'ischémie pendant la période de surveillance, mais a dévéloppé un infarctus myocardique au troisième jour postopératoire, suggérant une progression de la maladie coronarienne sous-jacente. L'imagerie préopératoire au thallium avec dipyridamole peut produire des scintigraphies faussement négatives chez des populations sélectives à haut risque.

Dipyridamole thallium imaging (DTI) is frequently used to detect the presence of marked coronary artery disease in patients who are unable to exercise. ${ }^{1}$ Dipyridamole causes coronary vasodilatation. This results in the preferential distribution of blood to areas supplied by normal coronary vessels and unchanged or decreased flow to areas of the myocardium supplied by stenotic coronary vessels which are already maximally dilated. ' In either case, the myocardium perfused distal to a stenosis receives relatively limited flow, causing a defect to appear on thallium imaging. As the vasodilatory effects of dipyridamole decrease, coronary blood flow is restored to areas of marginal perfusion. The myocardium, if viable, takes up thallium, resulting in visible perfusion on subsequent imaging. This is referred to as a reversible defect. If the myocardium is not viable (i.e., scar tissue from a previous infarction) a fixed thallium defect will be seen on subsequent imaging. A normal scan signifies an even distribution of flow without apparent defects throughout the myocardium.

Several authors have proposed that DTI provides the means for assessing perioperative cardiac risk before noncardiac surgery procedures. ${ }^{2,3}$ In prospective studies of consecutive vascular surgery patients, the presence of a reversible defect on DTI was associated with a $30-50 \%$ 
incidence of perioperative cardiac events, with few events reported in the group with normal scans or fixed defects. Several recent reports, however, have questioned the sensitivity of DTI in patients undergoing noncardiac surgery. Eagle $e t$ al. found five clinical variables (angina, age $>70 \mathrm{yr}$., diabetes, $\mathrm{Q}$ waves on ECG, and history of ventricular ectopy) which could be used to determine which patients would likely benefit from preoperative DTI. ${ }^{4}$ In a series of 200 vascular patients, DTI provided additional, predictive information only in those patients with one or two of the five clinical variables.

The presence of perioperative myocardial ischaemia has been associated with postoperative cardiac events. ${ }^{5-7}$ Because the lack of a reversible defect on DTI is thought to represent a low probability of perioperative cardiac events in the appropriate population, we suspected that the perioperative ischaemia pattern in those patients who sustained a myocardial infarction would provide insight into the cause of false negative scans. Therefore, we retrospectively reviewed our previously reported series of patients who were enrolled in a study of perioperative myocardial ischaemia between June 1989 and January $1990 .{ }^{8}$ Eleven patients had a clinically indicated preoperative DTI which demonstrated either a normal scan or fixed defect. Three (3/11) sustained postoperative myocardial infarction. The perioperative ischaemia pattern and preoperative risk factors in these three patients will be discussed.

\section{Case reports}

Study patients were monitored by calibrated amplitudemodulated AECG monitor (SpaceLabs ambulatory ECG model 90205, Redmond, WA) with modified bipolar lead $\mathrm{V}_{5}$ and in some cases bipolar lead $\mathrm{V}_{3}$ from the evening prior to noncardiac surgery through the third postoperative day. The AECG recordings were analyzed at the end of the monitoring period on lead $V_{5}$ for ST segment changes on a SpaceLabs FT2000 computerized analysis system and 24-hour ST-segment and heart rate trends were plotted. All changes observed in the trend plots were printed at 25 $\mathrm{mm} \cdot \mathrm{sec}^{-1}$ and the ECG strips were reviewed by two investigators blinded to clinical outcome. An ischaemic episode by AECG criteria was defined as either $\geq 0.1 \mathrm{mV}$ horizontal or downsloping ST segment depression or $\geq 0.2$ $\mathrm{mV}$ ST segment elevation measured at $60 \mathrm{msec}$ after the $\mathrm{J}$-point and persisting for at least one minute. The DTI scans were obtained based upon clinical indications and performed according to standard protocols using intravenous dipyridamole. ${ }^{9}$ Final interpretation of all thallium images was determined by one of two attending cardiologists, and the results were made available to the anaesthetist. All patients had 12-lead ECGs obtained on the first three postoperative days and more frequently as clinically indicated. Creatine kinase (CK) was measured every eight hours for the first $24 \mathrm{hr}$, and more frequently as clinically indicated (laboratory normal reference range 50-150 $\left.I U \cdot L^{-1}\right)$. The $C K$ isoenzyme analysis was performed by an electrophoretic method and $>2 \%$ was considered abnormal. In consultation with the Division of Cardiovascular Medicine, the diagnosis of a postoperative myocardial infarction was based upon the presence of the following criteria: an absolute elevation of $\mathrm{CK}>150 \mathrm{IU} \cdot \mathrm{L}^{-1}$ and CK-MB $>5 \%$, associated with chest pain and/or ECG changes. In each case, the opinion of the cardiologist involved with the patient's clinical care confirmed the diagnosis of acute MI independent of the study investigators.

\section{Case \#1}

The patient was a 75-year-old white woman scheduled for elective hemicolectomy. Past medical history included myocardial infarction six and two years before admission, diabetes and tobacco use. There was no history of angina, but physical activity was limited. The only medication was Theo-Dur. ECG revealed normal sinus rhythm with significant $Q$ waves in the precordial leads. Admission pulse was $108 \mathrm{bpm}$ and blood pressure was $118 / 70$.

This patient had three of the five clinical variables described by Eagle ( $Q$ waves, age, diabetes). The surgeon obtained a preoperative DTI based upon the clinical history. The scan demonstrated a fixed defect. Echocardiography revealed a $39 \%$ left ventricular ejection fraction.

The patient was premedicated with Benadryl $50 \mathrm{mg}$. Monitors included an intraarterial catheter. A lumbar epidural catheter was placed and tested with local anaesthetic. General anaesthesia was induced with thiopentone and maintained with isoflurane. During the operation a mild decrease in blood pressure occurred immediately after induction of anaesthesia which was treated with a vasopressor. After this, the intraoperative course was unremarkable. Tracheal intubation was continued at the conclusion of the case. Morphine was given via the epidural catheter in the ICU.

The endotracheal tube was removed on the evening of the surgical procedure. On the first postoperative day the patient required repeat endotracheal intubation for wheezing and respiratory distress. The CK-MB isoenzymes were obtained every eight hours during the first two postoperative days. Peak total CK occurred on the evening of the first postoperative day and was $281 \mathrm{IU} \cdot \mathrm{L}^{-1}$ with $6.8 \%$ MB fraction. Independent cardiology consultants diagnosed a sub-endocardial myocardial infarction. The patient died six months later of multiple system organ failure.

Although the patient did not demonstrate a reversible defect, she did demonstrate two episodes of ST segment 
elevation in bipolar lead $\mathrm{V}_{5}$ associated with heart rates of $130 \mathrm{bpm}$ during the preoperative period. Myocardial ischaemia continued throughout the intra- and postoperative period. There was one episode of ST elevation during induction which lasted $18 \mathrm{~min}$ and was associated with a heart rate of $103 \mathrm{bpm}$. A 40-min episode of ST segment elevation occurred on the evening of the day of surgery associated with a heart rate of $125 \mathrm{bpm}$ and systolic blood pressure of $80-90 \mathrm{mmHg}$ during weaning from mechanical ventilation.

\section{Case \#2}

The patient was a 72-yr-old white man scheduled for a femoral-popliteal bypass. Past medical history included diabetes, hypertension and stroke. The patient had no overt signs of coronary artery disease. Medications included metoprolol, hydrochlorthiazide, and an oral hypoglycemic. ECG revealed normal sinus rhythm with nonspecific ST-T wave changes. Admission pulse was 70 and blood pressure was $140 / 80$.

The patient had two of the five clinical risk factors described by Eagle (age, diabetes). The surgeon obtained a preoperative dipyridamole thallium scan which was normal.

The patient was premedicated with Benadryl $25 \mathrm{mg}$. Monitors included an intraarterial catheter. An epidural catheter was placed and local anaesthetic was used for the procedure. At the end of the procedure the patient was admitted to the ICU and a continous epidural narcotic infusion was used for analgesia. Cardiac enzymes obtained during the initial $24 \mathrm{hr}$ postoperatively were normal. On postoperative day one, the patient developed new ST segment depression of at least $2 \mathrm{~mm}$ in the precordial leads on 12-lead ECG. The ST segment depression persisted with new inversion of the $T$ waves anteriorly by the fourth postoperative day. Because these changes were not noted until the second postoperative day, CK-MB enzymes were not obtained until that time. Peak total CK occurred on the first set of enzymes and was $467 \mathrm{IU} \cdot \mathrm{L}^{-1}$ with a $4.8 \% \mathrm{MB}$.

The patient did not demonstrate preoperative ischaemia. The patient had a ten-minute episode of ST segment depression on the day of surgery at a heart rate of $88 \mathrm{bpm}$. The patient had multiple episodes of ST segment depression on the first postoperative day at similar heart rates betweeen 88-92 bpm. On the second postoperative day, the patient demonstrated continuous ST segment depression. The patient developed chest pain on the third postoperative day and required aggressive medical therapy for resolution of ischaemia. Although the initial CK-MB was $4.8 \%$, it was thought that the peak level occurred between the immediate 24 hours postoperatively and the second set of enzymes. Because of the initial elevated level of CK-MB in combination with classic ECG changes and haemodynamic alterations, the diagnosis of a postoperative MI was made by the cardiology consultants.

\section{Case \#3}

The patient was a 73-yr-old man scheduled for an elective aortobifemoral bypass. Past medical history included hypertension, tobacco use and a history of ventricular ectopy. There was no overt evidence of coronary artery disease. Medications included Theo-Dur. ECG revealed normal sinus rhythm with nonspecific $S T$ and $T$ wave changes. Admission heart rate was $84 \mathrm{bpm}$ and blood pressure was 132/80.

The patient demonstrated two of the five risk factors described by Eagle (age, ventricular ectopy). The surgeon obtained a preoperative DTI because of the nature of the surgery and clinical risk. The DTI scan was normal.

The patient did not receive a sedative premedication. Monitors included an intraarterial and pulmonary artery catheters. General anaesthesia was induced with thiopentone and fentanyl and maintained with nitrous oxide, fentanyl and isoflurane. The intraoperative course was unremarkable.

The trachea remained intubated in the ICU for four days postoperatively because of severe COPD. On the third postoperative day, the patient developed frequent ventricular ectopy, and CK enzymes were obtained. Peak total CK occurred on the evening of the third postoperative day and was $674 \mathrm{IU} \cdot \mathrm{L}^{-1}$ with $8.3 \% \mathrm{MB}$. An ECG during this episode demonstrated ST elevation anteriorly.

The patient demonstrated no evidence of pre-, intra-, or postoperative ischaemia for the first two postoperative days. The patient was not monitored by AECG on the third postoperative day due to technical problems.

\section{Discussion}

We observed three myocardial infarctions in patients who did not demonstrate a reversible defect. Two of these three demonstrated pre- or early postoperative myocardial ischaemia. When interpreting a DTI scan it is important to understand that the lack of redistribution signifies no differences in flow, but is not specific for the absence of myocardial ischaemia. This discrepancy between flow and ischaemia can result in the lower predictive value of DTI for perioperative ischaemic cardiac events.

Various technical features of thallium imaging may result in normal scans in patients with considerable coronary artery disease. Certain anatomical lesions are not well visualized on thallium imaging. Bertrand showed that DTI often did not identify left main or right coronary artery lesions. ${ }^{10} \mathrm{~A}$ normal scan may still be seen with severe triple vessel coronary disease. In such cases, blood supply to the myocardium is so marginal that all epicardial vessels are maximally dilated, and dipyridamole 
infusion is unable to alter the distribution of flow. Recently, postmortem examination of some patients with normal DTI was reported to demonstrate significant coronary stenoses in all major epicardial vessels. ${ }^{11}$ By summarizing five clinical reports of nonsurgical patients who had both coronary angiography and dipyridamole thallium imaging, Okada et al. reported that the overall sensitivity of the test for the detection of coronary artery disease was $79 \%$ and specificity was $95 \% .{ }^{12}$ In contrast, Mangano et al. found the sensitivity of dipyridamole thallium imaging for perioperative ischemia and adverse outcomes ranged from $40-54 \%$, and specificity was $65-71 \% .^{13}$ Those issues imply that some patients with both significant coronary artery disease and a high perioperative risk for cardiac morbidity may have normal scans on preoperative DTI.

The predictive value of a test depends upon the probability of the disease in the population. Eagle $e t$ al. found that if a patient exhibited three or more of the clinical risk factors, the likelihood of coronary artery disease was high regardless of the results of the DTI imaging. ${ }^{4}$ They recommended such patients undergo coronary angiography as an initial diagnostic test. This is a classic example of Bayesian analysis in which the post-test probability of disease depends on the pre-test probability. ${ }^{14}$

The DTI may manifest a fixed defect for patients who are at a considerable risk for ischaemia. Fixed defects in areas of viable myocardium supplied by arteries with marginal flow have been shown to reperfuse either with time or after a second infusion of thallium. ${ }^{15}$ Although still viable, the myocardium has minimal blood flow and risks severe ischaemia if stressed. McEnroe et al. reported the occurrence of perioperative cardiac events in several patients with fixed defects. ${ }^{16}$ The patients with fixed defects in our study demonstrated preoperative ischaemia, suggesting that these defects contained areas of viable myocardium. Therefore, as currently performed, DTI will sometimes fail to detect important coronary artery disease and the potential for ischaemia. In patient \#1, with three clinical risk factors, the likelihood of a false negative dipyridamole thallium scan was high.

Coronary artery disease may also progress during the perioperative period. The majority of myocardial infarctions in nonsurgical patients are the result of plaque rupture and thrombus formation in areas of minimal stenosis. ${ }^{17}$ Postoperatively, patients are often hypercoagulable. ${ }^{18}$ As early as 1938 , autopsy studies of patients who sustained a postoperative myocardial infarction and death were shown to have acute thrombosis and coronary occlusion. ${ }^{19}$ The occurrence of a myocardial infarction several days after surgery may well reflect such an acute thrombus formation.

In conclusion, the perioperative ischaemia pattern lends insight into the aetiology of false negative dipyridamole thallium scans. We believe that the high incidence of myocardial infarctions in our small series of negative scans is due to the high-risk nature of this population. Our work supports the need for a prospective study of DTI's predictive value in patients considered to be at high risk and undergoing diverse types of noncardiac surgery.

\section{Acknowledgement}

We wish to thank the surgeons of Yale-New Haven Hospital for allowing us to study their patients.

\section{References}

1 Iskandrian AS, Hes J, Askenass A, Segal BL, Auerbach $N$. Dipyridamole cardiac imaging. Am Heart J 1988; 115 : 432-43.

2 Boucher CA, Brewster DC, Darling RC, Okada RD, Strauss $H W$, Pohost GM. Determination of cardiac risk by dipyridamole-thallium imaging before peripheral vascular surgery. N Engl J Med 1985; 312: 389-94.

3 Eagle $K A$, Singer DE, Brewster DC, Darling RC, Mulley $A G$, Boucher CA. Dipyridamole-thallium scanning in patients undergoing vascular surgery. JAMA 1987; 257: 2185-9.

4 Eagle KA, Coley CM. Newell JB et al. Combining clinical and thallium data optimizes preoperative assessment of cardiac risk before major vascular surgery. Ann Intern Med 1989; 110: 859-66.

5 Mangano DT, Browner WS, Hollenberg $M$ et al. Association of perioperative myocardial ischemia with cardiac morbidity and mortality in men undergoing noncardiac surgery. N Engl J Med 1990; 323: 1781-8.

6 Pasternack PF, Grossi EA, Baumann FG et al. The value of silent myocardial ischemia monitoring in the prediction of perioperative myocardial infarction in patients undergoing peripheral vascular surgery. J Vasc Surg 1989; 10: 617-25.

7 Ouyang P, Gerstenblith G, Furman WR, Golueke PJ, Gottlieb SO. Frequency and significance of early postoperative silent myocardial ischemia in patients having peripheral vascular surgery. Am J Cardiol 1989; 64: 1113-6.

8 Fleisher LA, Rosenbaum SH, Hawes AD, Barash PG. The predictive value of preoperative silent ischemia for postoperative ischemic cardiac events in vascular and nonvascular surgical patients. Am Heart J 1991; 122: 980-6.

9 Leppo J, Boucher CA, Okada RD, Newell JB, Strauss HW, Pohost GM. Serial thallium-201 myocardial imaging after dipyridamole infusion. Diagnostic utility in detecting coronary stenoses and relationship to regional wall motion. Circulation 1982; 66: 649-57. 
10 Bertrand $M$, Coriat $P$, Baron JF, Barre E, Thomas D, Viars $P$. Dipyridamole thallium scan is not accurate in detecting coronary stenosis in patients undergoing abdominal aortic surgery. Anesthesiology 1990; 73: A86.

11 Chin W, Go R, Lenehan S, Underwood DA. Failure of dipyridamole-thallium myocardial imaging to detect severe coronary disease. Cleve Clin J Med 1989; 56: 587-9.

12 Okada RD, Glover DK, Leppo JA. Dipyridamole 201-T1 scintigraphy in the evaluation of prognosis after myocardial infarction. Circulation 1991; 84 (Suppl I): I-132-I-139.

13 Mangano DT, London MJ, Tubau JF et al. Dipyridamole thallium-201 scintigraphy as a preoperative screening test: a reexamination of its predictive potential. Circulation 1991: 84: 493-502.

14 Shuman P. Bayes' theorem. A review. Cardiol Clin 1984; 2: $319-28$.

15 Rocco TP, Dilsizian V, McKusick KA, Fischman AJ, Boucher CA, Strauss HW. Comparison of thallium reinjection with rest "reinjection" imaging for the detection of viable myocardium. Am J Cardiol 1990; 66: 158-63.

16 McEnroe CS, O'Donnell TF, Yeager A et al. Comparison of ejection fraction and Goldman risk factor analysis to dipyridamole-thallium imaging 201 studies in the evaluation of cardiac morbidity after aortic aneurysm surgery. J Vasc Surg 1990; 11: 497-504.

17 Fuster V, Stein B, Ambrose JA et al. Atherosclerotic plaque rupture and thrombosis. Evolving concepts. Circulation 1990; 82: (Suppl II) 47-59.

18 Ygge J. Changes in blood coagulation and fibrinolysis during the postoperative period. Am J Surg 1970; 119: 225-32.

19 Master AM, Dack S, Jaffe H. Postoperative coronary artery occlusion. JAMA 1938; 110: 1415-8. 